\title{
O DUPLO EM CORTÁZAR: O CASO DO CONTO “DESPUÉS DEL ALMUERZO"
}

\author{
Manoela da Silva Rodrigues (UFAM) ${ }^{1}$ \\ Esteban Reyes Celedón (UFAM) ${ }^{2}$
}

\begin{abstract}
"Siempre he escrito sin saber demasiado por qué lo hago, movido un poco por el azar, por una serie de casualidades: las cosas me llegan como un pájaro que puede pasar por la ventana." Julio Cortázar
\end{abstract}

\begin{abstract}
RESUMO: Em 1846, antes do surgimento da psicanálise, o jovem romancista russo Fiódor Dostoiévski (1821-1881) escreveu uma pequena novela, O Duplo (Двойник. Петербургская поэма, 1846), que abordava o conflito da personalidade de Goliadkin, funcionário público, que tenta se destacar dos demais, desempenhando com perfeições suas tarefas, mas é derrotado por ele mesmo, ou melhor, pelo seu duplo. Neste sentido, em 1964, o escritor argentino Julio Cortázar (1914-1984), no conto Después del Almuerzo, aborda a mesma temática, mas narrado por um jovem pré-adolescente. Numa primeira leitura, não sabemos ao certo de quem ou de que se trata; o que leva o leitor a imaginar que possa ser: um cachorro, um irmão com debilidades ou, até mesmo, um espírito. Neste conto se colocam noções de responsabilidade e culpa existentes da pré-adolescência, que tenta contrapor essa fase, sua vontade de se livrar deste ser a quem tem que acompanhar em seu passeio por ruas de Buenos Aires. Esta fase narrada coloca o duelo entre o jovem e este ser que tem suas vontades próprias de livramento em forma de culpa, querendo ser natural e humano, ora criança e ora querendo se tornar adulto, deixa claro que o duplo existe a todo instante, dentro e fora de si. O corpo exterior deste pré-adolescente pode aparentar maturidade, porém o Ser interior reluta com a consciência da infância; este ser não acompanha o exterior e vise versa. Neste trabalho analisaremos este duelo interior do protagonista, do ponto de vista da estética literária (herdeira da obra de Dostoiévski).
\end{abstract}

PALAVRAS-CHAVE: Julio Cortázar; Después del almuerzo; O duplo; Conto fantástico; Literatura argentina.

RESUMEN: En 1846, antes del surgimiento del psicoanálisis, el joven novelista ruso Fiódor Dostoiévski, escribió una pequeña novela, El doble, que abordaba el conflicto de personalidad de Goliadkin, funcionario público, que intenta destacarse de los demás, desempeñando con perfecciones sus tareas, pero es derrotado por él mismo, o mejor, por su doble. En este sentido, en 1964, Julio Cortázar, en el cuento Después del Almuerzo, aborda la misma temática, pero narrada por un joven pre-adolescente. En una primera lectura, no sabemos a lo cierto de quién o de qué se trata; lo que lleva al lector a imaginar que puede ser: un perro, un hermano con debilidades o, incluso, un espíritu. Este cuento se plantea nociones de responsabilidad y culpa

1 Graduada em Letras - Língua e Literatura Espanhola pela Universidade Federal do Amazonas. Faz parte do grupo de Estudos e Pesquisas A Crônica brasileira: dilemas, paradoxos e soluções de um gênero moderno - UFAM. Email: manoela2rodrigues@gmail.com

2Doutor em Letras Neolatinas pela UFRJ. Professor do curso de Letras Língua e Literatura Espanhola e do Programa de Pós-graduação em Letras na UFAM. Líder do Grupo de pesquisa A crônica brasileira: dilemas, paradoxos e soluções de um gênero moderno. Pós-doutorado em Estudos da Tradução no PGET-UFSC, onde também faz parte do Grupo de pesquisa do Núcleo Quevedo Estudos Literários e Traduções do Século de Ouro. 
existentes en la pre-adolescencia, que intenta contraponer esa fase, su voluntad de librarse de este ser a quien tiene que acompañar en su paseo por calles y lugares de Buenos Aires. La narrativa coloca el duelo entre el joven y este ser que tiene sus voluntades propias de liberación en forma de culpa, quiere ser natural y humano, continuar niño y hacerse adulto, deja claro que el doble existe a todo instante, dentro y fuera de sí. El cuerpo exterior de este pre-adolescente puede parecer maduro, pero el ser interior se reacia con la conciencia de la infancia; este ser no acompaña al exterior y vise versa. En este trabajo analizaremos este duelo interior del protagonista, desde el punto de vista de la estética literaria (heredera de la obra de Dostoievski).

PALABRAS CLAVE: Julio Cortázar; Después del almuerzo; El doble; Cuento fantástico; Literatura argentina.

\section{INTRODUÇÃO}

Este trabalho foi desenvolvido a partir de um artigo apresentado no III Colóquio Poético Literário com o tema: "Venga a jugar a la rayuela" realizado pela UFPA- Universidade Federal do Pará em 2015.

Julio Cortázar, nascido acidentalmente em Bruxelas em 1914, é um dos mais destacados escritores argentinos do passado século. Estudou Artes e Ensino e trabalhou como professor em várias cidades do interior da Argentina. Em 1951 ele viajou para Paris graças a uma bolsa de estudos. Depois disso, seu trabalho como tradutor da UNESCO permitiu-lhe que se estabelecesse permanentemente na capital francesa. Até então Julio Cortazar já havia publicado em Buenos Aires el poemário Presencia, com o pseudônimo Julio Denis, o poema dramático Los Reyes e a primeira de suas séries de histórias curtas, Bestiário, com evidentes características da estética de Jorge Luis Borges. Seu romance Rayuela (1963), com suas várias possíveis ordens de leitura, chocou o panorama literário de seu tempo. Cortázar morreu em Paris em 12 de fevereiro de 1984 e deixou como herança literária várias novelas e contos.

O conto Después del almuerzo, de Julio Cortázar, leva a uma reflexão do que vem a ser a companhia de um garoto que não se sente muito à vontade diante de ter que sair de casa logo após o almoço. Em primeiro lugar, levaremos em consideração que o almoço é um horário intermediário entre a manhã que acabou de passar e a tarde que começará. Isto nos permite entender que, levando para o lado do corpo físico e o desenvolvimento da criança, já passou a infância, porém ainda não entrou na tarde, que seria a fase adulta. Esse momento do dia seria a adolescência. Em segundo lugar, recorremos ao romancista russo, Fiódor Dostoiévski (18211881), que em 1846, mesmo antes do surgimento da psicanálise, escreveu uma pequena novela, $O$ Duplo, que abordava o conflito da personalidade de Goliadkin (personagem principal) funcionário público, que tenta ser diferente dos demais, buscando sempre fazer com perfeição seu trabalho, mas é derrotado por ele mesmo, ou melhor, pelo seu duplo. Em este sentido, em 
1964 Julio Cortázar, no conto Después del Almuerzo retoma a mesma temática - o duplo - mas narrado por um jovem pré-adolescente.

Neste duelo de seu eu, ora criança e ora querendo se tornar adulto, fica claro que o duplo existe a todo instante, dentro e fora de si. O corpo exterior deste pré-adolescente pode aparentar maturidade, porém o ser interior reluta com a consciência da infância. Numa primeira leitura, não sabemos ao certo de quem ou de que se trata; o que leva o leitor a imaginar que possa ser: um cachorro, um irmão com debilidades ou, até mesmo, um espírito. Mas, ao lermos o jovem Dostroiévski, O Duplo, reconhecemos o conflito interno do sujeito, ou seja, trata-se do mesmo personagem: por um lado, Ele pessoa, pelo outro, Ele como desejo.

\section{NOVELA E CONTO}

Se a princípio, os gêneros literários novela e conto tem as suas diferenças estéticas, que veremos a seguir, entretanto, compartem algumas características, por exemplo, a intenção de convencer o público, por meio da verossimilhança, diria Aristóteles. Para entendermos melhor algumas dessas diferenças, vamos ao auxílio do próprio Cortázar, não do escritor, mas sim do professor de literatura que, no outono de 1980, proferiu uma série de conferências em Berkeley, Califórnia. Parte destas aulas, que duraram dois meses, está registrada no livro Clases de Literatura, editado pelo professor catalão Carles Álvarez Garriga, doutor em filologia, com tese sobre os prólogos de Julio Cortázar.

Para Cortázar, a diferença entre novela e conto está em que a novela tem sua trama modificada a todo instante, ela é aberta, pode prosseguir infinitamente, segundo as necessidades da trama e vontade do escritor em determinar um final ou dar sequência, não existe um prazo exato para o seu término. Cortázar afirma que:

Una novela puede ser muy corta o casi infinita, algunas novelas terminan y uno se queda con la impresión de que el autor podría haber continuado, y algunos continúan porque años después escriben una segunda parte. (CORTÁZAR, 2013, p. 29)

Já o conto tem um final determinado, quem o lê fica com ele na memória. Neste sentido, Cortázar o compara à figura da esfera, por ser geometricamente perfeita, uma vez que se fecha em si mesma, todos os seus pontos estão à mesma distância do centro:

Alguna vez he comparado el cuento con la noción de una esfera, la forma geométrica más perfecta en el sentido de que está totalmente cerrada en sí misma y cada uno de los infinitos puntos de su superficie son equidistantes del invisible punto central. (CORTÁZAR, 2013, p. 30) 
O professor escritor Cortázar prossegue sua definição de novela e conto, e os compara com o cinema e a fotografia respectivamente. Um filme, assim como a novela, pode ter uma continuidade ou não, é aberta, podemos ter uma segunda parte. Já a fotografia, a semelhança do conto, está determinada, a imagem é aquela mesma que a gente vê, não há nada a mais para além das suas bordas, no entanto, incita à imaginação a pensar em algo a mais, todavia não é outra fotografia:

Una película es como una novela, un orden abierto, un juego donde la acción y la trama podrían o no prolongarse... en cambio, la fotografía me hace pensar siempre en el cuento... proyecta una especie de aura fuera de sí misma y deja la inquietud de imaginar lo que había más allá. (CORTÁZAR, 2013, p. 30)

O conto Después del almuerzo, talvez seja uma esfera um pouco mais complexa, uma fotografia com detalhes imperceptíveis a uma simples mirada (ou leitura), necessitando de uma análise aprofundada. Neste conto, há detalhes que, para a maioria das pessoas, podem passar despercebidos, por exemplo, o duplo do garoto protagonista. Ele está aí, está dado, mas a princípio, não o percebemos como duplo, pensamos que se trata de outro garoto (irmão ou um animal de estimação).

Durante a narrativa, atitudes da fase de infância confrontam-se a todo instante com as atitudes da fase de amadurecimento, a fase de adolescente. Como nos seguintes trechos:

Lo primero que contesté fue que no, que lo llevara otro, que por favor me dejaran estudiar en mi cuarto. Iba a decirles otras cosas, explicarles por qué no me gustaba tener que salir con él, pero papá dio un paso adelante y se puso a mirarme en esa forma que no puedo resistir, me clava los ojos y yo siento que se me van entrando cada vez más hondo en la cara, hasta que estoy a punto de gritar y tengo que darme vuelta y contestar que sí, que claro, en seguida.

Aqui, neste parágrafo, o garoto não quer sair para passear, mas o desejo dos pais de querer que ele saia é superior, de forma que o pai o intimida com um olhar; o garoto quer reagir, como adulto, porém, atua como uma criança, todavia se contém e, resignado, aceita o que o pai ordena. Desta forma, ele sai:

Por la mañana había llovido y las veredas de Buenos Aires están cada vez más rotas, apenas se puede andar sin meter los pies en algún charco. Yo hacía lo posible para cruzar por las partes más secas y no mojarme los zapatos nuevos, pero en seguida vi que a él le gustaba meterse en el agua, y tuve que tironear con todas mis fuerzas para obligarlo a ir de mi lado. A pesar de eso consiguió acercarse a un sitio donde había una baldosa un poco más hundida que las otras, y cuando me di cuenta ya estaba completamente empapado y tenía hojas secas por todas partes. 
Devido às chuvas, as ruas de Buenos Aires estavam cheias de poças d'águas, o garoto tenta caminhar por onde estivesse mais seco, por onde seu pai o levaria, mas, como está sozinho, seu duplo infantil, rebelde assim como toda criança levada, não resiste às poças, e acaba por se sujar nelas.

Tuve que pararme, limpiarlo, y todo el tiempo sentía que los vecinos estaban mirando desde los jardines, sin decir nada pero mirando. No quiero mentir, en realidad no me importaba tanto que nos miraran (que lo miraran a él, y a mí que lo llevaba de paseo); lo peor era estar ahí parado, con un pañuelo que se iba mojando y llenando de manchas de barro y pedazos de hojas secas, teniendo que sujetarlo al mismo tiempo para que no volviera a acercarse al charco.

A vergonha, que sente o garoto ao perceber que as pessoas estão lhe observando, é algo característico de um adolescente tímido, que já tem noção de certo e errado. Logicamente, um adulto não insistiria em meter os pés na lama, diferente de uma criança, que além de meter os pés na lama e se sujar, acha tudo muito divertido, e o faz sem nem imaginar o que vão pensar dela. Porém, para o garoto, o pior é ter que lutar contra si mesmo, tentar dominar esse outro ser, o eu rebelde para que não voltasse às poças.

Además yo estoy acostumbrado a andar por las calles con las manos en los bolsillos del pantalón, silbando o mascando chicle, o leyendo las historietas mientras con la parte de abajo de los ojos voy adivinando las baldosas de las veredas que conozco perfectamente desde mi casa hasta el tranvía.

Neste momento, se justifica que quando, supostamente desacompanhado do seu duplo infantil, consegue ter jeito de adolescente, tanto que, consegue andar pelas ruas com tranquilidade, despreocupado das poças, mascando chiclete, inclusive lendo, pois conhece com exatidão cada lugar por onde passa.

O passeio continua; pega o bondinho; senta-se, mas:

Me tuve que levantar (y ahora dos o tres pasajeros me miraban) y acercarme al otro asiento. «Dos boletos», le dije. Cortó uno, me miró un momento, y después me alcanzó el boleto y miró para abajo, medio de reojo. «Dos, por favor», repetí, seguro de que todo el tranvía ya estaba enterado. El chinazo cortó el otro boleto y me lo dio, iba a decirme algo pero yo le alcancé la plata y me volví en dos trancos a mi asiento, sin mirar para atrás.

O garoto ao ir pagar as passagens, sente-se incomodado com as pessoas que olham para ele, novamente a vergonha e timidez tomam conta, atitudes de adolescente. Ao pagar diz que são duas passagens; já o cobrador, cobra só uma passagem, o garoto insiste em pagar duas; o cobrador fica sem entender, logicamente por existir só um, o garoto, o duplo ninguém o vê, este é apenas fruto de sua mente. Mais adiante, supostamente, o duplo começa a brincar no ônibus, 
atitude de criança. Ele, o garoto, tem de tomar conta, fica olhando a cada vez que conta até dez.

Esta atitude pode ser considerada dupla: ou ele está tomando conta do seu duplo, ou ele está brincando de contar até dez. Conta até dez, como no boxe, ou seja, referência clara a uma briga, um combate:

Entonces me puse a contar hasta diez, igual que en las peleas, y eso venía a ser más o menos media cuadra. Al llegar a diez me daba vuelta disimuladamente, por ejemplo arreglándome el cuello de la camisa o metiendo la mano en el bolsillo del saco, cualquier cosa que diera la impresión de un tic nervioso o algo así.

Desta maneira, continua o passeio e a briga do garoto (pré-adolescente) e seu duplo (infantil). Um no papel do adulto consciente; o outro uma criança querendo brincar. Durante o conto, o narrador compartilha informações detalhadas de alguns lugares conhecidos de Buenos Aires, incluindo, desta forma, o leitor no passeio:

A mí me gusta mucho la Plaza de Mayo, cuando me hablan del centro pienso en seguida en la Plaza de Mayo. Me gusta por las palomas, por la Casa de Gobierno y porque trae tantos recuerdos de historia, de las bombas que cayeron cuando hubo revolución, y los caudillos que habían dicho que iban a atar sus caballos en la Pirámide. Hay maniseros y tipos que venden cosas, en seguida se encuentra un banco vacío y si uno quiere puede seguir un poco más y al rato llega al puerto y ve los barcos y los guinches.

Logo o garoto retoma à sua angustia de estar acompanhado de seu duplo e arquiteta uma maneira de se ver livre do mesmo:

Yo no sé en qué momento me vino la idea de abandonarlo ahí; lo único que me acuerdo es que estaba pelándole un maní y pensando al mismo tiempo que si me hacía el que iba a tirarles algo a las palomas que andaban más lejos, sería facilísimo dar la vuelta a la pirámide y perderlo de vista.[...]yo pensé solamente que lo podía abandonar ahí y andar solo por el centro con las manos en los bolsillos, y comprarme una revista o entrar a tomar un helado en alguna parte antes de volver a casa.

Enfim o garoto decide abandonar seu duplo:

Le seguí dando manises un rato pero ya estaba decidido, y en una de esas me hice el que me levantaba para estirar las piernas y vi que no le importaba si seguía a su lado o me iba a darle manises a las palomas. Les empecé a tirar lo que me quedaba, y las palomas me andaban por todos lados, hasta que se me acabó el maní y se cansaron. Desde la otra punta de la plaza apenas se veía el banco; fue cosa de un momento cruzar a la Casa Rosada donde siempre hay dos granaderos de guardia. 
Porém a culpa de abandonar o seu duplo lhe causa mal estar: "me empezó a doler el estómago... yo quería respirar y me costaba, entonces tenía que quedarme quieto y esperar que se pasara el calambre.” Recusa a ajuda de alguns homens que o viram passar mal:

unos muchachos me miraron un momento y uno le dijo al otro que yo estaba descompuesto, pero yo moví la cabeza y dije que no era nada, que siempre me daban calambres, pero se me pasaban en seguida. Uno dijo que si yo quería que fuera a buscar un vaso de agua, y el otro me aconsejó que me secara la frente porque estaba sudando. Yo me sonreí y dije que ya estaba bien, y me puse a caminar para que se fueran y me dejaran solo.

Então o garoto, agoniado com o sentimento de culpa, retorna, correndo, para buscá-lo (seu duplo) e levá-lo de volta para casa:

No sé cuánto tardé en llegar otra vez a la Plaza de Mayo. A la mitad de la subida me caí, pero volví a levantarme antes que nadie se diera cuenta, y crucé a la carrera entre todos los autos que pasaban por delante de la Casa Rosada. Desde lejos vi que no se había movido del banco, pero seguí corriendo y corriendo hasta llegar al banco, y me tiré como muerto mientras las palomas salían volando asustadas y la gente se daba vuelta con ese aire que toman para mirar a los chicos que corren, como si fuera un pecado. Después de un rato lo limpié un poco y dije que teníamos que volver a casa.

No caminho para casa, ele volta com a sensação de bem estar e tranquilidade pois consegue dominar seu duplo que parece ter atitudes mais "comportadas" de um pré-adolescente, como atravessar as ruas sem se atrapalhar, sentar no ônibus e não ficar andando ou trocando de cadeira, a pesar de que, na calçada, insiste em querer se meter nas poças de água, mas é contido:

Por suerte esta vez no se encaprichó al cruzar las calles, y el tranvía estaba casi vacío al comienzo del recorrido, así que lo puse en el primer asiento y me senté al lado y no me di vuelta ni una sola vez en todo el viaje, ni siquiera al bajarnos: la última cuadra la hicimos muy despacio, él queriendo meterse en los charcos y yo luchando para que pasara por las baldosas secas.

Antes de chegar em casa, o garoto imagina que seus pais ficariam felizes ao constatar que o filho tem a responsabilidade de sair sozinho e ir ao centro da cidade sem causar problemas:

Pero no me importaba, no me importaba nada. Pensaba todo el tiempo: «Lo abandoné», lo miraba y pensaba: «Lo abandoné», y aunque no me había olvidado del Paseo Colón me sentía tan bien, casi orgulloso. A lo mejor otra vez... No era fácil, pero a lo mejor... Quién sabe con qué ojos me mirarían papá y mamá cuando me vieran llegar con él de la mano. Claro que estarían contentos de que yo lo hubiera llevado a pasear al centro. 
Mas como entender a figura (mito) do duplo na literatura?

\section{O DUPLO NA LITERATURA}

No interessante ensaio de Juan Herrero Cecilia, Figuras y significaciones del mito del doble en la literatura, que segue a classificação de Jourde e Tortonese (Visages du doublé. Une thème littéraire, 1996), encontramos a sistematização do duplo segundo duas vertentes, a saber: o duplo subjetivo e o duplo objetivo. O primeiro é de caráter interno, o personagem se projeta num duplo por ele imaginado, um eu desejo de ser diferente. Já o segundo é de caráter externo, o personagem vê um duplo de outrem.

O tema da duplicidade, desde o princípio da literatura fantástica, no final do século XVIII, tem causado a inquietude de muitos escritores e tem ganhado espaço por uma série de personagens inspirados nesse "desdobramento", seja pelo inconformismo do seu eu, ou pelo duelo de personalidades e aparências, além de uma excitação nos limites da identidade e alteridade. Apresentando-se como uma problemática relevante e pertinente, na qual, o mito do duplo se converte em um dos temas mais significativos da literatura fantástica, tanto pela sua estética e da interação entre o lógico e o natural quanto na ordem em que se relaciona com o sobrenatural de forma inexplicável.

No Romantismo alemão ressurge o interesse pelo mito do duplo. Como exemplo, tomamos a Jean-Paul que em 1796 publica sua obra Siebenkas (recentemente traduzida ao espanhol). O Protagonista, cansado e insatisfeito da sua tediosa vida, finge sua morte e assume outra identidade, abandona a mulher e passa a se aventurar pelo mundo. Jean-Paul Richter, que também escreveu uma Introducción a la Estética, criou o conceito de Doppelgänger (desdobramento ou duplo), para retratar a imagem desdobrada do eu como indivíduo externo, ou seja, um eu - outrem. Neste caso o indivíduo vê a si próprio em alguém que se apresenta ao mesmo tempo como duplo autônomo, ou como um duplo "fantástico" capaz de produzir angústia e desassossego, perturbando a ordem natural e normal das coisas. Esse "desdobramento" percebido pela consciência do indivíduo coloca em cheque a sua identidade e a diferença diante de "outrem".

Tomando como referência esta proposta de Jean-Paul, verificamos que o duplo de Dostoievski está relacionado às questões pessoais que o indivíduo passa com relação a sua identidade e de como a sociedade pode influenciar no seu comportamento. Para o escritor russo, todo ser humano tem seu lado que pende para o negativo ou positivo, o bem e o mal, neste contraste de personalidade surge o duplo. É o querer e o não querer, é poder ser algo que ainda 
não se tem condições de ser ou se a têm opta em não poder. São circunstâncias que a sociedade impõe, forçando o lado da dualidade em cada ser. Para um eu que não satisfaz às expectativas da sociedade, este cria um duplo dele mesmo, no entanto, com os atributos que imagina serem os esperados pelos demais.

Da mesma forma, no conto de Cortázar, coloca-se esse protagonista como exemplo de que o duplo existe, até mesmo desde quando o indivíduo está em fase de amadurecimento. Não se trata mais de um adulto com problemas de trabalho, no conto do argentino, é um préadolescente lutando com seu lado infantil. Fica claro que é em casa que esse duplo aparece, desde o conflito que o garoto possui, por ter suas vontades deixadas de lado para respeitar a do seu pai, e em seguida, quando vai às ruas, e se vê forçado a realizar o que a sociedade impõe.

Porém, como todo conto, nos deparamos com uma surpresa:

los padres siempre están contentos de esas cosas; pero no sé por qué en ese momento se me daba por pensar que también a veces papá y mamá sacaban el pañuelo para secarse, y que también en el pañuelo había una hoja seca que les lastimaba la cara.

O garoto volta para casa, mas, antes de entrar, pensa: talvez seus pais também fossem como ele, também, ao saírem à rua, tinham que tomar conta de si mesmo, dos seus duplos, e limpar-lhes o rosto com o lenço que retém a sujeira, as folhas secas que arranham e machucam. Assim como no início, ele tinha que limpar e secar seu duplo com o lenço, seus pais, da mesma forma, de alguma maneira, também machucassem sua própria cara. Talvez, todos nós tenhamos nosso duplo.

\section{A LITERATURA FANTÁSTICA}

A Literatura Fantástica é um dos gêneros literários que têm como características: a noção de tempo, fatalidade, destino, premonição e o duplo. Algumas dessas características podem estar presentes no texto de forma única ou mesclada. Quando temos um fenômeno que não é distinguível do que seja real ou imaginado, mas pode ser explicado naturalmente ou sobrenatural, esta duas maneiras de explicar é o que pode ser entendido como o fantástico.

Podemos verificar algumas citações de estudiosos do assunto:

"En lo fantástico verdadero, siempre existe la posibilidad exterior y formal de una explicación simple de los fenómenos, pero al mismo tiempo esa explicación está privada por complemento de probabilidad interna." (Vladimir Soloviov; Pag.24); "A veces es necesario tener una puerta de salida para una explicación natural, pero debería agregar que esta puerta debe 
ser lo bastante estrecha como para que no se pueda utilizar." (Montague Rhode James. Pag.25); "El héroe siente en forma continua y perceptible la contradicción entre los dos mundos, el de lo real y el de lo fantástico, y él mismo se asombra ante las cosas extraordinarias que lo rodean." (Olga Reinmann. Pag.25).

Os dois primeiros referem-se ao fantástico em relação ao leitor, no último em relação ao personagem, como a personagem está envolvida nas situações dos dois mundos, a realidade e o fantástico, e ela mesma se surpreenderá com o que acontece no meio da sua situação de hesitação.

Para Cortázar o fantástico é compreendido da seguinte maneira:

\footnotetext{
"Yo era un niño muy realista por la simple razón de que lo fantástico nunca me pareció fantástico sino una de las posibilidades y de las presencias que puede darnos la realidad cuando por algún motivo directo o indirecto alcanzamos a abrirnos esas imprevisiones." (CORTÁZAR, 2013).
}

Além disso, segundo Todorov os textos fantásticos devem ter três condições:

1. O texto tem que forçar o leitor a considerar o mundo dos personagens como o mundo das pessoas vivas; 2. Explicação natural e sobrenatural dos eventos; 3. O leitor adota certa atitude em relação ao texto.

Logo, o primeiro e o terceiro constituem o gênero de fato; o segundo pode ou não ser cumprido. Mas, de todas as maneiras, na maioria dos textos fantásticos, podemos encontrar as três condições.

\section{CONSIDERAÇÕES FINAIS}

O Fantástico é um gênero literário que possibilita a vacilação entre o mundo real e o sobrenatural, que foge do tempo e do espaço.

No conto Después del Almuerzo, esse recurso se apresenta no personagem pré-adolescente, no momento em que é levado por situações confusas, em que seu duplo lhe confronta, ora com atitudes de criança ora com comportamentos de adulto. Mas, para o leitor, que é familiarizado ao gênero fantástico, Después del Almuerzo, assim como várias outras histórias de Julio Cortázar, é um excelente exemplo desse gênero e a leitura, assim como a interpretação, do conto não causa estranhamento ou confusão, o leitor logo percebe o que está em jogo.

Después del Almuerzo nos atrai para questões de reflexão. A figura do garoto é um meio de refletir para questões que a sociedade impõe, como a cobrança de atitudes responsáveis de um garoto ainda na sua pré-adolescência. Sendo que no conto essa cobrança parte dos próprios pais do garoto. 
De certa maneira, podemos afirmar que qualquer pessoa tem seu duplo, contraditório, dentro de si. Embora possamos negar sua existência, esse outro estará sempre presente, mesmo em nossos momentos de distrações.

A rejeição por alguns interesses da sociedade, não concordando com uma ideia ou pensamento, já nos leva a ser esse duplo.

\section{REFERÊNCIAS}

BIOGRAFIAS Y VIDAS. La enciclopedia biográfica en línea. "Julio Cortázar". Disponible en: <http://www.biografiasyvidas.com/biografia/c/cortazar.htm> Acesso em 24 de set. 2018.

CECILIA, Juan Herrero. Figuras y significaciones del mito del doble en la literatura: teorías explicativas. Çédille, Revista de estudos franceses. Monografia 2 (2011). Pág. 15-48. Disponível em:<https://cedille.webs.ull.es/M2/02herrero2.pdf> Acesso em 02 de out. 2018.

CORTÁZAR, Julio. Después del Almuerzo. Disponível em: $<$ https://ciudadseva.com/texto/despues-del-almuerzo/> Acesso em 15 de out. 2018.

CORTÁZAR, Julio. Clases de Literatura: Berkeley, 1980. Edição de Carles Álvarez Garriga. Santiago (Chile): Alfaguara, 2013.

GARCÍA, Guillermo López. La división del yo en los personajes dostoievskianos: el caso de El Doble. Publicado en las Actas de las II Jornadas de rusistas españoles - Universidad de Valencia, 1998. Pág.148-156. Disponível em: <http://www.lapaginadefinitiva.com/weblog/articulosglopez/dostoievski.PDF> Acesso em $01 \mathrm{de}$ out. 2018.

HERRERA, Jose Gregorio Cassiani. Julio Cortázar-Después del almuerzo. Disponível em:〈http://cassianiher.blogspot.com.br/2012/11/julio-cortazar-despues-del-almuerzo.html> Acesso em 15 de out. 2018.

TODOROV, Tzvetan. Introducción a la Literatura Fantástica. $1^{a}$ edición, Buenos Aires: Paidós, 2006.

ZAVALA, Hernán Lara. Cortázar y sus dobles. Revista de la Universidad de México. Núm. 128(2014).Pág.13-16. Disponível em: <http://www.revistadelauniversidad.unam.mx/ojs_rum/index.php/rum/article/view/16361> Acesso em: 02.out.2018. 